Members commented on several issues related to meeting content and processes. They thought that their joint meetings with the PI and IS group were valuable for developing the stakeholder-driven research agenda. Several suggested that joint meetings should have occurred earlier and more often. Most members said that the language used by the research team in meetings was appropriate for people who did not have a background in healthcare. However, one member noted that he sometimes looked for definitions of terms after meetings, and another said that the research team used too many acronyms. Members were concerned that people who participated in meetings remotely, or who did not use a computer and email, may not have had comparable opportunities to contribute. Finally, members wished that they had heard more about how the researchers would build on the project and whether they would involve the PCS group in future projects. "We did all this work-what's going to happen now? It was not as clear as you would hope it would be."

In summary, PCS members identified several elements of engagement that worked well in this project and several areas for improvement. The collegial atmosphere established by the research team helped members feel comfortable sharing their stories and perspectives. Members highly valued meetings that involved the PI and IS group, as these interactions offered an opportunity to see the direct impact of PCS contributions on the project. Based on member's comments, we identified additional strategies that can help us enhance the experience of stakeholders on future projects.

1. Conduct a structured orientation to prepare stakeholders. ${ }^{7}$ Content should address the project goal and intended outcomes; role of PCS group members and other stakeholders; and mutual expectations for stakeholders and the project team.

2. Provide a comparable meeting experience for all stakeholders, regardless of differences in access to computers/smartphones or ability to participate in person. If members participate remotely, facilitators can use round-robin activities to ensure that all members have opportunities to contribute.

3. Use plain language that everyone can understand during meetings, in materials, and in communications.

4. Provide meaningful closure by explicitly discussing the research team's plans for the future, including future involvement of the PCS group.
The results of this evaluation represent findings from one group of patient and caregiver stakeholders and are not generalizable to all HAI research that involves patient stakeholders. However, the strategies for effective engagement that emerged may provide a useful starting point for HAI researchers planning to involve patients and caregivers as advisors.

Author ORCIDs. Betty L. Kaiser, (iD 0000-0001-6119-0205

Acknowledgements. None.

Financial support. This work was supported by the Department of Veterans' Affairs Quality Enhancement Research Initiative program (grant no. PEC 15-248) in partnership with the VA National Center for Patient Safety, and partially funded through a Patient-Centered Outcomes Research Institute Eugene Washington Engagement Award (grant no. 2680-UWisc).

Conflicts of interest. All authors report no conflicts of interest relevant to this article.

\section{References}

1. Rawson TM, Castro-Sanchez E, Charani E, et al. Involving citizens in priority setting for public health research: implementation in infection research. Health Expect 2018;21:222-229.

2. Keating JA, Brys N, Knobloch MJ, Safdar N. Patients as stakeholders: developing a patient-centered healthcare epidemiology research agenda. Infect Control Hosp Epidemiol 2018:1-2.

3. Rawson TM, Moore LSP, Castro-Sanchez E, et al. Development of a patientcentred intervention to improve knowledge and understanding of antibiotic therapy in secondary care. Antimicrob Resist Infect Control 2018;7:43.

4. Ahmad R, Iwami M, Castro-Sanchez E, et al. Defining the user role in infection control. J Hosp Infect 2016;92:321-327.

5. Guise JM, O'Haire C, McPheeters M, et al. A practice-based tool for engaging stakeholders in future research: a synthesis of current practices. J Clin Epidemiol 2013;66:666-674.

6. Brys N, Keating JA, Knobloch MJ, Safdar N. Engaging patients in healthcare epidemiology research: a case example. Am J Infect Control 2019;47: 139-143.

7. Kaiser B, Thomas G. Patient Advisor Toolkit 1: Orientation for Patient Advisory Committees (PAT-1). Wisconsin Network for Research Support, University of Wisconsin- School of Nursing, and Health Innovation Program. https://www.hipxchange.org/PAT-1. Published 2018. Accessed (May 20, 2019).

\title{
Current status of infection control professionals in a Chinese city
}

\author{
Peijin Zhang MM and Liling Tang MB \\ Department of Hospital Infection Management, Yijishan Hospital of Wannan Medical College, Wuhu City, Anhui, China
}

To the Editor-Healthcare-associated infection (HAI) management is an important component of medical quality management; it directly affects the quality of healthcare and patient safety. ${ }^{1} \mathrm{With}$

Author for correspondence: Liling Tang MB, Yijishan Hospital of Wannan Medical College, 2 West Zheshan Rd, 241001, Anhui Province, China. Email: yjsygk2017@sina.com

Cite this article: Zhang P and Tang L. (2019). Current status of infection control professionals in a Chinese city. Infection Control \& Hospital Epidemiology, 40: 949-950, https://doi.org/10.1017/ice.2019.143 advances in medical technology, the HAI problem has become more and more prominent, which has put forward higher work requirements for infection control professionals (ICPs). More than 40 years ago, the Centers for Disease Control and Prevention (CDC) conducted the national Study on the Efficacy of Nosocomial Infection Control (SENIC). ${ }^{2}$ Its findings suggested that an adequate staffing ratio of ICPs had lower rates of HAI. Similarly, a number of other studies reported that high levels of 
Table 1. Demographics and Work Situations of Infection Control Professionals (ICPs) in Wuhu City

\begin{tabular}{|c|c|c|c|}
\hline Variable & $\begin{array}{c}\text { Secondary } \\
\text { Hospital }(n=24) \text {, } \\
\text { No. }(\%)\end{array}$ & $\begin{array}{c}\text { Tertiary } \\
\text { Hospital } \\
(n=22) \\
\text { No. }(\%)\end{array}$ & $\begin{array}{c}P \\
\text { Value }\end{array}$ \\
\hline Gender & & & .581 \\
\hline Male & $2(8.33)$ & $4(18.18)$ & \\
\hline Female & $22(91.67)$ & $18(81.82)$ & \\
\hline Age, y & & & .376 \\
\hline$\leq 30$ & $6(25.00)$ & $4(18.18)$ & \\
\hline $31-40$ & $2(8.33)$ & $5(22.73)$ & \\
\hline$\geq 41$ & $16(66.67)$ & $13(59.09)$ & \\
\hline Marital status & & & .581 \\
\hline Married & $22(91.67)$ & $18(81.82)$ & \\
\hline Single & $2(8.33)$ & $4(18.18)$ & \\
\hline Education background & & & $<.001$ \\
\hline Junior college & $12(50.00)$ & $2(9.09)$ & \\
\hline Undergraduate & $12(50.00)$ & $13(59.09)$ & \\
\hline Graduate & $0(0.00)$ & $7(31.82)$ & \\
\hline Major & & & .097 \\
\hline Clinical medicine & $1(4.17)$ & $3(13.64)$ & \\
\hline Nursing & $21(87.50)$ & $13(59.09)$ & \\
\hline Preventive medicine & $2(8.33)$ & $4(18.18)$ & \\
\hline Others & $0(0.00)$ & $2(9.09)$ & \\
\hline Years of service & & & .561 \\
\hline$\leq 5$ & $13(54.17)$ & $12(54.54)$ & \\
\hline $6-10$ & $8(33.33)$ & $5(22.73)$ & \\
\hline$\geq 11$ & $3(12.50)$ & $5(22.73)$ & \\
\hline $\begin{array}{l}\text { Reasons of ICPs engaged in } \\
\text { HAI management }\end{array}$ & & & 0.020 \\
\hline Administrative arrangement & $21(87.50)$ & $12(54.55)$ & \\
\hline Personal preference & $1(4.17)$ & $4(18.18)$ & \\
\hline Employment needs & $0(0.00)$ & $4(18.18)$ & \\
\hline Others & $2(8.33)$ & $2(9.09)$ & \\
\hline
\end{tabular}

ICPs played an important role in reducing HAI rates. ${ }^{3,4}$ To our knowledge, little information is available regarding the current status of ICPs in China published in the English language.

In January 2019, we collected the demographic characteristics and occupational statuses of 46 ICPs from 5 tertiary hospitals and 16 secondary hospitals where independent nosocomial infection and control departments had been set up. Demographics and work situations of ICPs are shown in Table 1. Among the investigated ICPs, $86.96 \%$ were female, and $63.04 \%$ were aged $\geq 41$ years. Most ICPs had taken undergraduate courses (69.57\%) and were in a nursing specialty (73.91\%). Except education background, the differences in gender, age, marital status, major, and years of service were not statistically significant between ICPs in secondary and tertiary hospitals $(P>.05)$. Surprisingly, the most common causes for engaging in HAI management were administrative arrangements, which accounted for $71.74 \%$.
The ICP teams were mainly composed of female nurses. This composition is consistent with the findings from other cities in China concerning ICP characteristics. ${ }^{5,6}$ A few hospitals hire retired nurses to ensure the quantity of ICPs in accordance with the requirements. ${ }^{7}$ However, the proportion of nurses will gradually decrease in the future. As the prevention, management, and control of infection have developed, most hospitals have begun to recruit candidates from a wide range of clinical or healthcarescience backgrounds, especially public health graduates. Vassallo et $\mathrm{al}^{8}$ proposed that those hiring ICPs should consider masters of public health graduates as candidates whose epidemiologic skills could help to drive the future of this profession in decreasing HAIs and promoting patient safety and service quality.

Moreover, most ICPs had worked $<5$ years, which reflects the instability of the management team. Most ICPs were engaged in HAI management due to administrative arrangements. Previous studies have suggested that the main causes of the instability in the management team are heavy workload, insufficient leadership attention, and low pay in China. ${ }^{5,9}$ Only by solving these problems can we cultivate high-quality ICPs.

In conclusion, the HAI management team in Wuhu city has basically formed. The structure of ICPs in tertiary hospitals is better than that of secondary hospitals, but the personnel structure is still unreasonable, and the professional level needs to be further improved.

\section{Author ORCIDs. Peijin Zhang MM, (DD 0000-0001-7323-2804}

Acknowledgments. We would like to thank the Nosocomial Infection Control Center of Wuhu City for supporting the study.

Financial support. No financial support was provided relevant to this article.

Conflicts of interest. All authors report no conflicts of interest relevant to this article.

\section{References}

1. Rodríguez-Baño J, del Toro MD, López-Méndez J, Mutters NT, Pascual A. Minimum requirements in infection control. Clin Microbiol Infect 2015;21:1072-1076.

2. Haley RW, Quade D, Freeman HE, Bennett JV. The SENIC Project. Study on the efficacy of nosocomial infection control (SENIC project): summary of study design. Am J Epidemiol 1980;111:472-485.

3. Parry GJ, Tucker JS, Tarnow-Mordi WO, Group UNSS. Relationship between probable nosocomial bacteraemia and organisational and structural factors in UK neonatal intensive care units. Qual Saf Health Care 2005;14:264-269.

4. Richet HM, Benbachir M, Brown DE, et al. Are there regional variations in the diagnosis, surveillance, and control of methicillin-resistant Staphylococcus aureus? Infect Control Hosp Epidemiol 2003;24:334-341.

5. Zhang ZG, Han M, Yang ZP, et al. Current situation of full-time healthcareassociated infection management staff in Xianyang City of Shaanxi Province. Chin J Infect Control 2017;16:635-638.

6. Zhang YH, Zhang HJ, Jin FL, Zhang J. Current status of full-time staff of nosocomial infections control in Gansu province. Chin J Nosocomiol 2013;23:3448-3449.

7. Sun B. Nosocomial infection in China: management status and solutions. Am J Infect Control 2016;44:851-852.

8. Vassallo A, Boston KM. The master of public health graduate as infection preventionist: navigating the changing landscape of infection prevention. Am J Infect Control 2019;47:201-207.

9. Zhang ZG, Wei QX, Wang XM, et al. Current situation and job stability of full-time staff for nosocomial infection management in traditional Chinese medicine hospital of Shaanxi Province. Occup and Health 2018;34: 3099-3102. 